\title{
Edukasi Menggunakan Booklet Preconception Care Meningkatkan Pengetahuan dan Self Efficacy Calon Pengantin
}

\author{
Yunita Wulandari $^{1^{*}}$, Wahyu Dwi Aguissafutri ${ }^{2}$, Wahyuningsih Safitri ${ }^{3}$ \\ ${ }_{1,2,3}$ Fakultas Ilmu Kesehatan, Universitas Kusuma Husada Surakarta \\ *Email: yunitastikeskh@gmail.com
}

\begin{abstract}
Background: The bride and groom are part of the preconception care program targets. The period before conception for the bride and groom is very important to consider in order to prepare for a healthy pregnancy. Aim of this study is to analize the effect of giving the preconception care booklet on the knowledge and self efficacy of the prospective bride and groom (catin). Methods: The research method used was quantitative with a quasi experimental approach pre and post test without control. with a total sample of 56 people (28 catin), assessing knowledge and self-efficacy using a questionnaire. The intervention given to respondents was education with preconception booklets. Results: The results of the analysis showed that in the pre and post groups both knowledge and self-efficacy obtained a p-value of $0.000<0.05$ so that there was a difference between the pre-test and post-test levels of knowledge on reproductive health and sef efficacy of the prospective bride and groom. This means that Ha is rejected and $\mathrm{Ho}$ is accepted. Conclusion: Recommendation in this study is the influence of giving the Preconception Care Booklet on the knowledge and Self Efficacy of the bride and groom.
\end{abstract}

Keywords: booklet preconception care, groom, knowledge, self efficacy

\section{PENDAHULUAN}

World Health Organization (WHO) dalam Suistainable Development Goals (SDGs) mempunyai target menurunkan Angka Kematian Ibu (AKI) menjadi 70/100.000 kelahiran hidup pada tahun 2030 (Johnston, 2016; Kemenkes RI, 2014). AKI diindonesia yang ditargetkan menurun menjadi 102 pada tahun 2015 tidak tercapai, karena menurut laporan SDKI, 2012 AKI di Indonesia masih berada pada angka $228(41,5 \%)$ per 100.000 kelahiran hidup (Kementrian Kesehatan, 2017). Indonesia berada pada peringkat ke tujuh di antara negara-negara ASEAN (Johnston, 2016; Kementrian Kesehatan, 2017; Riskesdas, 2013).

AKI yang tinggi di Indonesia disebabkan oleh beberapa hal. Faktor penyebab terbanyak adalah perdarahan (32\%), hipertensi dalam kehamilan (25\%) dan infeksi (2\%) (Badan Pusat Statistik, 2018). Upaya percepatan penurunan Angka Kematian Ibu bertujuan menjamin agar setiap ibu mampu mengakses pelayanan kesehatan yag berkualitas, antara lain pelayanan kesehatan ibu hamil, pertolongan persalinan oleh tenaga kesehatan terlatih, perawatan pasca persalinan bagi ibu dan bayi, perawatan khusus, rujukan jika terjadi komplikasi dan pelayanan KB (pasca salin) (Profil Kesehatan Indonesia, 2019).

Upaya preventif, promotif maupun kuratif yang dilakukan pemerintah untuk menurunkan AKI diantaranya program Rumah Sakit Sayang Ibu, Program Upaya Percepatan Penurunan AKI (kementrian Kesehatan, 2017). Upaya upaya tersebut merupakan bagian dari upaya kesehatan berkelanjutan yaitu sejak preconception care, antenatal care, postnatal care (Shaleh et al., 2014). Preconception care adalah pemberian intervensi kesehatan berupa biomedis, perilaku dan sosial kepada wanita dan pasangan sebelum menikah yang bertujuan untuk meningkatkan status kesehatan mereka 
dan mengurangi perilaku dan faktor individu dan lingkungan yang dapat berkontribusi pada kesehatan ibu dan anak yang buruk (WHO, 2013). Negara yang telah berhasil melaksanakan program ini adalah Italia, Belanda, Amerika Serikat untuk negara maju dan Bangladesh, Filiphina, Sri Lanka untuk negara berpenghasilan menengah-rendah (WHO, 2012).

Pasangan pengantin merupakan
bagian dari sasaran program
preconception care. Masa sebelum konsepsi bagi pasangan pengantin sangat penting untuk diperhatikan dalam rangka mempersiapkan kehamilan yang sehat (Astantekin, 2019). Pelaksanaan preconception care di Indonesia belum maksimal yaitu baru sebatas tindakan vaksinasi tetanus toxoid (TT). Salah satu daerah yang telah melaksanakan program preconception care berdasarkan studi literatur adalah di Kecamatan Ujung Tanah Makassar.

Pelaksanaan preconception care meliputi akses pelayanan kesehatan wanita prakonsepsi diantaranya pengukuran antropometri untuk menilai status gizi kemudian dilanjutkan dengan konsultasi gizi, Pemeriksaan $\mathrm{Hb}$, karena wanita pada masa prakonsepsi yang akan memasuki masa kehamilan akan berbahaya jika mengalami anemia. Pemeriksaan reproduksi untuk deteksi dini kanker, pemeriksaan tanda vital dan imunisasi TT untuk untuk melindungi ibu dan calon bayi (Amalia \& Siswantara, 2018) (Shaleh et al., 2014).

Berdasarkan penelitian Wulandari, 2016 tentang preconception care pada pasangan pengantin dihasilkan booklet yang berisi tentang materi yang berkaitan dengan persiapan bagi catin sebelum pernikahan, booklet ini terbukti efektif untuk meningkatkan pengetahuan catin tentang prekonsepsi dan materi kesehatan reporduksi pra nikah. Self efficacy yaitu keyakinan bahwa seseorang akan menjadi mampu melakukan tugas dengan sukses. (Fitriana et al., 2018). Keyakinan diri (Self Efficacy) diperlukan oleh catin, dimana catin merasa mampu untuk menyelesaikan tugas-tugas yang dimilikinya dan mampu menyelesaikan masalahnya. Bedanya dengan penelitian sebelumnya adalah booklet yang digunakan apda penelitian ini adalah booklet dari kemenkes dengan amteri yang lebih luas.

Berdasarkan studi pendahuluan yang dilakukan oleh peneliti di puskesmas Sibela menunjukkan bahwa intervensi preconception care yang dilakukan oleh bidan maupun perawat kepada calon pasangan pengantin baru belum berjalan secara terpadu, program yang telah ada yaitu imunisasi TT dan tes kehamilan. Berdasarkan studi awal yang dilakukan peneliti diketahui bahwa fasilitas untuk pemberian pendidikan kesehatan belum ada baik berupa booklet dan leaflet.

\section{METODE PENELITIAN}

Penelitian ini dilakukan di Puskesmas Sibela bulan Juni-Juli 2019 dengan jumlah sampel sebanyak 56 orang (28 pasangan). Rancangan penelitiannya pra eksperimen (pre experiment) dengan desain pre and post test without control. Kriteria sampel adalah calon pengantin yang akan melangsungkan pernikahan yang pertama dan saat pengambilan data datang ke puskesmas untuk imunisasi TT.

Perbedaan antara sebelum dan sesudah diberikan perlakuan dinilai dengan cara membandingkan nilai sebelum pemberian booklet yaitu pada saat suntik TT, dan sesudah yaitu 1 minggu setelah pemebrian booklet dengan 
melalui media online untuk pemberian kuesioner posttestnya. Intervensi yang diberikan pada penelitian ini dilakukan dengan menggunakan pemberian booklet mengenai prekonsepsi pada catin. Instrument yang digunakan untuk melihat pengetahuan adalah kuesioner yang dibuat sendiri oleh peneliti dan sudah dilakukan uji validitas lebih dari 0,361 sedangkan reliabilitas dengan hasil 0,796. Untuk kuesioner self efficacy menggunakan kuesioner yang sudah baku.

\section{HASIL PENELITIAN}

Pengetahuan Sebelum Pemberian Booklet tergambar pada tabel 1 berikut

Tabel 1. Pengetahuan Sebelum Pemberian Booklet KESPRO CATIN (N=56)

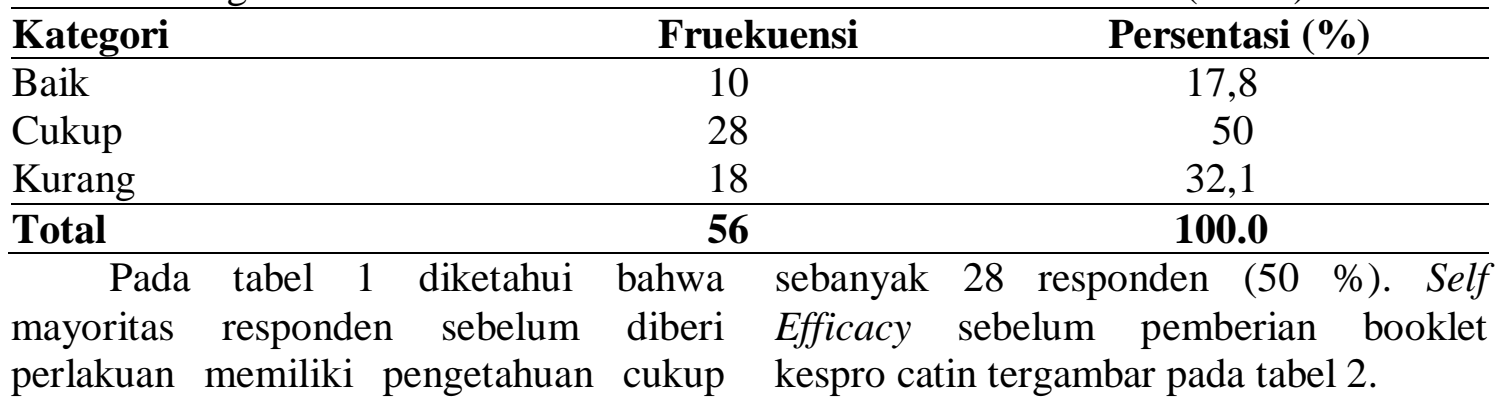

Tabel 2. Self Efficacy Sebelum Pemberian Booklet KESPRO CATIN

\begin{tabular}{lclc}
\hline Kategori & Fruekuensi & Persentasi (\%) \\
\hline Baik & 6 & 10,7 \\
Cukup & 30 & 53,5 \\
Kurang & 20 & 35,7 \\
\hline Total & \multicolumn{2}{c}{$\mathbf{5 6}$} & $\mathbf{1 0 0 . 0}$ \\
\hline \multicolumn{1}{c}{ Pada tabel 2 diketahui sebagian } & sebanyak $30 \quad$ responden $(53,5 \%)$ \\
besar responden sebelum diberi perlakuan & Pengetahuan sesudah pemberian booklet \\
memiliki Self Efficacy yang cukup & kespro catin tampak pada tabel 3.
\end{tabular}

Tabel 3. Pengetahuan Sesudah Pemberian Booklet KESPRO CATIN (N=56)

\begin{tabular}{lrc}
\hline Kategori & Fruekuensi & Persentasi (\%) \\
\hline Baik & 51 & 91 \\
Cukup & 5 & 8,9 \\
Kurang & 0 & 0 \\
\hline Total & $\mathbf{5 6}$ & $\mathbf{1 0 0 . 0}$ \\
\multicolumn{4}{c}{ Pada tabel diatas diketahui bahwa } & Efficacy & sesudah & pemberian booklet \\
\multicolumn{4}{c}{ sebagian besar responden sesudah diberi } & kespro catin tergambar pada tabel 4.
\end{tabular}

perlakuan memiliki pengetahuan yang

baik sebanyak 51 responden $(91 \%)$. Self 
Tabel 4. Self Efficacy Sesudah Pemberian Booklet KESPRO CATIN (N=56)

\begin{tabular}{lcc}
\hline Kategori & Fruekuensi & Persentasi (\%) \\
\hline Baik & 32 & 57,1 \\
Cukup & 21 & 37,1 \\
Kurang & 3 & 5,3 \\
\hline Total & $\mathbf{5 6}$ & $\mathbf{1 0 0 . 0}$ \\
\hline \multicolumn{2}{c}{ Pada tabel 4 diatas dapat diketahui } & booklet preconception care terhadap \\
bahwa sebagian besar responden sesudah & peningkatan pengetahuan dan self efficacy \\
diberi perlakuan memiliki Self Efficacy & calon pengantin (Catin). Terdapat pada \\
yang baik yaitu sebanyak 32 responden & tabel 5.
\end{tabular}

$(57,1 \%)$. Pengaruh edukasi dengan

Tabel 5. Hasil Uji Wilcoxon

\begin{tabular}{lcc}
\hline Data Penelitian & $\mathbf{Z}$ & p-value \\
\hline Pengetahuan pre-post & $-6,570$ & 0,000 \\
Self Efficacy pre-post & -6.623 & 0,000 \\
\hline
\end{tabular}

Hasil uji Wilxocon menunjukkan

Edukasi memlalui booklet etrbukti efektif bahwa pada kelompok pre dan post baik pada pengetahuan dan self efficacy diperoleh $p$-value $0,000<0,05$ sehingga ada perbedaan antara pre test dan post test tingkat pengetahuan maupun self efficvacy pada calon pengantin.

\section{PEMBAHASAN}

Hasil penelitian sebelum diberikan booklet KESPRO CATIN mayoritas responden memiliki pengetahuan cukup sebanyak 28 responden $(50 \%)$. Pengetahuan kesehatan reproduksi bagi calon pengantin menjadi hal sangat penting. Pasangan suami istri harus memiliki kesehatan lahir dan batin yang baik, salahsatunya adalah kesehatan reproduksinya berada pada kondisi baik. Pengetahuan yang cukup tentang kesehatan reproduksi sebelum pernikahan perlu mendapatkan intervensi agar pengetahuan calon pengantin menjadi lebih baik.

Hasil penelitian sesudah diberikan booklet KESPRO CATIN sebagian besar responden memiliki pengetahuan yang baikyaitu sebanyak51 responden $(91 \%)$. untuk meningkatkan pengetahuan calon penagntin. Informasi ini sangat diperlukan oleh calon pengantin sehingga motivasi calon pengantin meningkat saat mulai di berikan booklet dalam bentuk softfile digrup edukasi. Catin merasakan kebutuhan akan informasi ini juga menjadi salahsatu motivasi untuk membaca dan terlibat aktif dalam diskusi. Booklet dikemas dengan sangat komunikatif dan materi yang diberikan merupakan ilmu yang berkaitan dengan fungsi, hak reproduksi dan seksual, organ reproduksi, persiapan pra nikah, kesetaraan gender, informasi tentang kehamilan, perslainan dan nifas. Menurut penelitian Hidayati (2016) pengetahuan yang baik tentang kesehatan reproduksi berkorelasi dengan kesiapan menikah seseorang.

Pengetahuan sebagai salah satu aspek yang menunjukkan kemampuan seseorang untuk mengerti dan menggunakan kemampuan terhadap segala sesuatu yang telah dipelajarinya. Pengetahuan adalah domain yang sangat penting untuk terbentuknya tindakan 
seseorang (overt behaviour). Berdasarkan hasil penelitian bahwa pengetahuan yang baik diharapkan akan berdampak pada peningkatan sikap dan perilaku dari CATIN terkait kesehatan reproduksi.

Sebelum diberi perlakuan memiliki Self Efficacy cukup yaitu sebanyak 30 responden $(53,5 \%)$. Menurut Pudjiastuti (2012) self efficacy yaitu keyakinan seseorang terhadap kemampuannya untuk menyelesaikan tugas dan mampu menyelesaikan masalah untuk mencapai tujuan. Keyakinan seseorang terhadap keberhasilannya memiliki efek bervariasi, yaitu: keyakinan mempengaruhi tindakan seseorang untuk memilih, berapa besar usaha yang dilakukan terhadap apa yang diinginkan, dan berapa lama bertahan dalam menghadapi rintangan. Sumbersumber self efficacy yaitu pengalaman performansi atau pengalaman, karena pasangan catin sangat berharap menjadi pasangan suami istri yang bahagia. Pengalaman adalah salsahsatu proses yang akan bermakna dalam meningkatkan self efficacy catin baik melihat dari pengalaman orang tua, kelaurga terdekat maupun lingkungan (Kang, 2020).

Mayoritas responden sesudah diberi perlakuan memiliki Self Efficacy yangbaik yaitu sebanyak32 responden $(57,1 \%)$. Seseorang dengan tingkat pengetahuan yang baik juga akan memiliki tingkat self efficacy yang baik pula, hal ini disebabkan karena tingkat pengetahuan responden mempengaruhi tingkat self efficacy yang dimiliki oleh responden. Adapun faktor yang mempengaruhi self efficacy antara lain faktor orientasi kendali diri, faktor situasional, status atau peran individu dalam lingkungan dan faktor insentif ekternal atau reward (Karsten et al., 2019). Penelitian ini sejalan dengan penelitian yang dilakukan oleh Kamtono
(2015) dengan hasil penelitian ini didapatkan self efficacy responden dalam penanganan kejang demam masuk dalam kategori sedang sebanyak 59,1\%. Peningkatan pengetahuan berkorelasi dengan peningkatan keyakinan dari seseorang.

Hasil uji Wilxocon menunjukkan bahwa pada kelompok pre dan terdapat perbedaan antara pre test dan post test tingkat pengetahuan maupun sef efficvacy pada calon pengantin. Menurut Albert Bandura dalam Friedman dan Schustack (2008), pengetahuan didapat melaui proses pembelajaran observasi dan mengamati orang lain melakukan suatu hal. Mengamati orang lain melakukan suatu hal termasuk kedalam pengalaman. Sumber-sumber self efficacy terdiri dari pertama, pengalaman permormasi yaitu prestasi yang pernah dicapai masa lalu. Sebagai sumber performasi masa lalu menjadi pengubah self efficacy yang paling kuat pengaruhnya. Kedua, pengalaman vikarius diperoleh melalui model sosial atau mengamati orang lain. Self efficacy akan meningkat ketika mengamati keberhasilan orang lain, sebaliknya self efficacy akan menurun jika mengamati orang lain yang kira-kira kemampuannya sama dengan dirinya ternyata gagal. Ketiga, persuasi sosial atau dorongan dari orang lain yang menyemangati kita untuk mampu dalam mengerjakan sesuatu. Keempat, keadaan emosi yang mengikuti suatu kegiatan akan mempengaruhi self efficacy dibidang kegiatan itu. Emosi yang kuat, takut, cemas, stress, dapat mempengaruhi self efficacy. Pendapat serupa juga dikemukakan Albert Bandura dalam Friedman dan Schustack (2008) mengenai faktor-faktor yang mempengaruhi sel efficacy yaitu pengalaman keberhasilan 
pada tugas sebelumnya, melihat orang lain secara kompeten, dorongan sebagai penyemangat dan tingkat stimulasi fisiologis yang memberikan informasi apakah kita bisa menghadapi situasi (Evrianasari \& Dwijayanti, 2016)(Fitriana et al., 2018).

Menurut Pujiastuti (2012), faktorfaktor yang mempengengaruhi self efficacy salah satunya adalah lingkungan. Status atau peran individu dalam lingkungan sangat mempengaruhi self efficacy dikarenakan jika seseorang dilingkungan tersebut memiliki kedudukan tinggi dan memiliki lingkungan yang positif akan menambah self efficacy seseorang. Dari beberapa faktor diatas diketahui faktor self efficacy yang paling berpengaruh yaitu pencapaian prestasi dimasa lalu atau pengalaman. Pengalaman sukses yang dilakukan sebelumnya memberikan indikasi langsung tentang tingkat dan kompeten seseorang. Prestasi sebelumnya menunjukkan kemampuan kita dan memperkuat perasaan self efficacy seseorang. Kedua, yaitu lingkungan dikarenakan jika lingkungan memberikan dampak positif, respon dari setiap individu akan memberikan dampak positif juga terhadap perilakunya yang akan menambah self efficacynya.

Menurut Budiman dan Riyanto (2013), suatu cara untuk memperoleh kebenaran pengetahuan dengan cara mengulangi kembali pengetahuan yang diperoleh dalam pemecahan masalah masa lalu. Lingkungan merupakan segala hal yang ada di sekitar seorang, baik lingkungan fisik kemudian biologis, dan sosial. Lingkungan berpengaruh pada proses diterimanya pengetahuan pada individu yang berada dalam suatu lingkungan. Ini terjadi karena interaksi timbal balik atau tidak. Faktor yang mempengaruhi pengetahuan yaitu pendidikan, informasi/ media massa, sosial budaya ekonomi, lingkungan, pengalaman dan usia. Jadi hubungan antara pengetahuan dan self efficacy (Goodfellow et al., 2017; Karsten et al., 2019).

Berdasarkan hasil penelitian yang didapatkan bahwa tingkat self efficacy yang baik pada responden mempunyai pengetahuan yang baik. Catin yang menjadi responden dalam penelitian ini memiliki pengetahuan baik dapat menjawab sebagian pertanyaan dengan benar, serta memiliki keyakinan baik dalam pemahaman tenang kesehatan reproduksi dan seksualitas.

\section{KESIMPULAN DAN SARAN}

Sebagian besar responden sebelum diberi perlakuan memiliki pengetahuan yang cukup yaitu sebanyak 28 responden $(50 \%)$. Sebagian besar responden sebelum diberi perlakuan memiliki Self Efficacy yang cukup yaitu sebanyak 30 responden $(53,5 \%)$. Sebagian besar responden sesudah diberi perlakuan memiliki pengetahuan yang baik yaitu sebanyak 51 responden $(91 \%)$. Sebagian besar responden sesudah diberi perlakuan memiliki Self Efficacy yang baik yaitu sebanyak 32 responden $(57,1 \%)$. Pengetahuan dan self efficacy diperoleh sehingga terdapat perbedaan antara pre test dan post test tingkat pengetahuan maupun self efficvacy pada calon pengantin dengan p-value 0,000 $<0,05$. Booklet Preconception Care memberikan dampak terhadap peningkatan pengetahuan dan self efficacy bagi calon pengantin.

Rekomendasi untuk penelitian selanjutnya adalah bisa menggunakan 
variable lain misalnya sikap, perilaku, status kesehatan ibu hamil dan beberapa outcomes kehamilan yang lain.

\section{DAFTAR RUJUKAN}

Amalia, R., \& Siswantara, P. (2018). Efektivitas Penyuluhan Kesehatan Reproduksi pada Calon Pengantin di Puskesmas Pucang Sewu Surabaya. In Jurnal Biometrika dan Kependudukan (Vol. 7, Issue 1, p. 29).https://doi.org/10.20473/jbk.v7i 1.2018.29-38

Astantekin, F. O. (2019). The Effects and Related Factors of Health Literacy Status and Self-Efficacy of Pregnant Women. 12(3), 1815-1825.

Badan Pusat Statistik. (2018). Profil Kesehatan Ibu dan Anak.

Berglund, A., \& Lindmark, G. (2016). Preconception health and care (PHC) - a strategy for improved maternal and child health. Upsala Journal of Medical Sciences, 121(4), 216-221. https://doi.org/10.1080/03009734.20 16.1191564

Dean, S., Rudan, I., Althabe, F., Webb Girard, A., Howson, C., Langer, A., Lawn, J., Reeve, M. E., Teela, K. C., Toledano, M., Venkatraman, C. M., Belizan, J. M., Car, J., Chan, K. Y., Chatterjee, S., Chitekwe, S., Doherty, T., Donnay, F., Ezzati, M., ... Bhutta, Z. A. (2013). Setting Research Priorities for Preconception Care in Low- and Middle-Income Countries: Aiming to Reduce Maternal and Child Mortality and Morbidity. PLoS
Medicine, 10(9). https://doi.org/10.1371/journal.pmed .1001508

Evrianasari, N., \& Dwijayanti, J. (2016). Pengaruh Buku Saku Kesehatan Reproduksi Dan Seksual Bagi Catin Terhadap Pengetahuan Catin Tentang Reproduksi Dan Seksual Di Kantor Urusan Agama (Kua) Tanjung Karang Pusat Tahun 2017. Jurnal Kebidanan, Vol 3(4), 157168.

Fitriana, R. N., Suryawati, C., \& Zubaidah, Z. (2018). Effect of Peer Education Model on Knowledge and Self-Efficacy of Children in the Prevention of Physical Sexual Violence. Belitung Nursing Journal, 4(1),51-57.

https://doi.org/10.33546/bnj.341

Goodfellow, A., Frank, J., Mcateer, J., \& Rankin, J. (2017). Improving preconception health and care: a situation analysis. 1-8. https://doi.org/10.1186/s12913-0172544-1

Johnston, R. B. (2016). Arsenic and the 2030 Agenda for sustainable development. Arsenic Research and Global Sustainability - Proceedings of the 6th International Congress on Arsenic in the Environment, AS 2016, $12-14$. https://doi.org/10.1201/b20466-7

Kang, S. Y. (2020). Gender Di ff erences in Factors Influencing Self-E ffi cacy Toward Pregnancy Planning among College Students in Korea. 
Karsten, M. D. A., Oers, A. M. Van, Groen, H., Mutsaerts, M. A. Q., \& Poppel, M. N. M. Van. (2019). Determinants of successful lifestyle change during a 6-month preconception lifestyle intervention in women with obesity and infertility. 2463-2475.

Kemenkes RI. (2014). Profil Kesehatan Indonesia 2014.

Kementrian Kesehatan. (2017). No Title Profil Kesehatan Republik Indonesia tahun 2017.

Riskesdas. (2013). Riset Kesehatan Dasar.

Shaleh, F., Thaha, A. R., Salam, A., Prodi, B., Fakultas, I. G., Masyarakat, K., \& Hasanuddin, U. (2014). Family Support in Women's Health Services Utilization in District Preconception and Land City Makassar. 1-13. https://core.ac.uk/download/pdf/254 96665.pdf

WHO. (2012). Meeting to develop a global consensus on preconception care to reduce maternal and childhood mortality and morbidity. WHO Headquarters, Geneva Meeting Report. Geneva: ..., 78. http://scholar.google.com/scholar?hl $=$ en $\& b \operatorname{tnG}=$ Search $\& \mathrm{q}=$ intitle:Meeti ng+to+Develop+a+Global+Consens us+on+Preconception+Care+to+Red uce+Maternal+and+Childhood+Mor tality+and+Morbidity\#0\%5Cnhttp:// scholar.google.com/scholar?hl=en\& $\mathrm{btnG}=$ Search \&q=intitle:Meeting $+\mathrm{t}$ 